\title{
Scalable Production of Nanostructured Particles using Atomic Layer Deposition ${ }^{\dagger}$
}

\author{
Aristeidis Goulas and J. Ruud van Ommen* \\ ${ }^{1}$ Department of Chemical Engineering, Delft University of Technology, the Netherlands
}

\begin{abstract}
Core-shell nanoparticles and other nanostructured particles have high potential in applications such as heterogeneous catalysis and energy conversion and storage. However, a hurdle in their utilization is that typically, large amounts of such nanostructured materials are required. Gas-phase coating using atomic layer deposition (ALD, a variant of chemical vapour deposition) can be used to provide the surface of a particle with either an ultrathin continuous coating or a decoration of nanoclusters. When carried out in a fluidized bed, ALD is an attractive way of producing nanostructured particles with excellent scale-up potential.

We demonstrate the fabrication of catalysts by deposition of the active phase $(\mathrm{Pt})$ on fluidized nanoparticles $\left(\mathrm{TiO}_{2}\right.$ P25) at atmospheric pressure. We show that ALD is a technique that 1) guarantees efficient use of the precursor; 2) allows precise control of the size and loading; 3) can be used for low and medium loading of catalysts by adjusting the number of repeated cycles; 4) leads to high-quality (low impurities level) end-products.
\end{abstract}

Keywords: atomic layer deposition, nanostructured particles, clusters, platinum, titania, catalyst

\section{Introduction}

In recent years, researchers have proposed a wide range of novel nanostructured materials for applications such as catalysis (Canlas et al., 2012; Li and Somorjai, 2010) and photovoltaic devices (Jancar et al., 2010; Kamat, 2008). Often, such materials use nanostructured particles as building blocks. In this paper, we will use the term nanostructured particles for particles of at least two materials, typically a host particle (not necessarily $<100 \mathrm{~nm}$ ) onto which a second material is present in some structured way, e.g. as a film or set of clusters with dimensions $<100 \mathrm{~nm}$. For most applications in catalysis and energy conversion and storage, large amounts of such materials are required. Most of the current synthesis routes for nanostructured particles, however, do not take into account the scalability of the process. It is not considered whether the synthesis of small amounts of materials in stirred flasks could be taken to some large-scale reactor to produce commercial amounts of materials. Moreover, the amount of waste produced in small-scale synthesis typically receives little or no attention.

While for research purposes it is not a problem to produce $100 \mathrm{~g}$ of waste to obtain $1 \mathrm{mg}$ of a desired product,

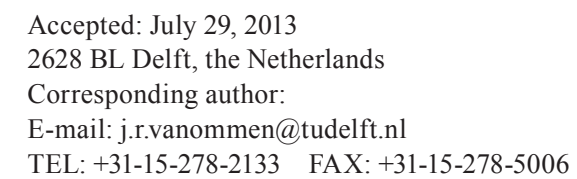

such a ratio is unacceptable at industrial scale. Sheldon (1992) proposed quantifying the efficiency of chemical processes by the $E$-factor: the mass ratio of waste to desired product. Table 1 gives the $E$-factor for some industry segments. It is clear that nanomaterial production has the poorest performance by far. If nanomaterials are going to be widely applied in medicine, energy conversion and storage, their product throughput will increase to approximately the levels of pharmaceuticals and fine chemicals, respectively, which will give unacceptable amounts of waste. If we do not improve the manufacturing routes for nanomaterials drastically, it will lead to a low public acceptance and fewer market introductions of products based on such materials.

One of the reasons why the current synthesis of nanostructured particles is so polluting is that a combination of solvents and surfactants is often used, and the produced concentration of nanoparticles is very low; this yields very high $E$-factors. Moving to the gas phase eliminates the use of solvents, and is therefore intrinsically cleaner. Moreover, gas-phase processes are typically easier to scale up when nanostructured materials (Wegener et al., 2011) are concerned, although there are exceptions. For example, graphene can be more easily synthesized in large amounts in the liquid phase than in the gas phase (Coleman, 2012). When producing nanostructured particles in the gas phase, two basic approaches are possible:

(1) Directly synthesizing the nanostructured particles from precursors. 
Table 1 Annual product throughput for a typical plant and $E$-factor comparison for different material classes (based on Sheldon (2007) and Eckelman et al. (2008)).

\begin{tabular}{cccc}
\hline Industry segment & $\begin{array}{c}\text { Annual product } \\
\text { throughput }(\log \mathrm{kg})\end{array}$ & $\begin{array}{c}\text {-factor } \\
\text { Oil refining }\end{array}$ & $\begin{array}{c}\text { Typical amount of waste } \\
(\log \mathrm{kg})\end{array}$ \\
\hline Bulk chemicals & $7-9$ & $\sim 0.1$ & 9 \\
Fine chemicals & $5-7$ & $<1-5$ & 8 \\
Pharmaceuticals & $3-6$ & $5-50$ & 6 \\
Nanomaterials & $2-3$ & $25-100$ & 6 \\
\hline
\end{tabular}

(2) First producing the host or core particles, and then depositing the second material on them.

The first approach has the advantage of minimizing the number of steps in the production process; it can be considered as an example of process intensification. Several illustrative examples of this approach can be found in literature (Knijnenburg et al., 2013; Minnermann et al., 2013; Stepuk et al., 2012). However, it is not always straightforward to control the obtained morphology, and tuning of parameters might be needed when moving to a new combination of materials. The second approachseparating particle production and particle decorationgives more degrees of freedom. Moreover, it has the advantage that commercially available particles can be used. It will depend on the individual application which of the two approaches is preferred. In this paper, we will focus on the second approach, and especially on its second step: depositing nanostructured material on already available particles.

For the well-controlled deposition of material at the nanoscale, a number of approaches are available. Some of them are line-of-sight methods, and are therefore not easily applicable to particles; examples are e-beam deposition (Laukaitis et al., 2006) and sputtering (Ferguson et al., 2008). Other methods can be applied to particles, but are not so easy to scale-up. An example is electrospraying deposition of nanoparticles (Ellis et al., 2010; Yurteri et al., 2010), which might be useful for pharmaceutics production, but could be cumbersome for applications that require large amounts of materials. Chemical vapour deposition (CVD) and similar techniques can be applied to particles and have a good scale-up potential, but have difficulty in reaching nanoscale precision. Atomic layer deposition (ALD) is a modified version of CVD that can achieve such precision. We will discuss it in more detail in the next section.

This paper will discuss ALD as a method of producing nanostructured particles that is scalable and has a limited production of waste. We will use the deposition of platinum nanoclusters on titania nanoparticles as an example.

\section{Atomic layer deposition for the production of nanostructured particles}

\subsection{Atomic layer deposition}

Atomic layer deposition (ALD) is a technique that relies on the distinct, consecutive binding of two (or more) compounds in a combined structure under a self-limiting chemisorption/reaction scheme. ALD presents basic selfassembly characteristics (Kim et al., 2009). However, one can argue whether it fully matches the definition of self-assembly as given by Gates et al. (2005): the spontaneous organization of two (or more) components to form larger aggregates by means of covalent and/or non-covalent bonds. Nevertheless, ALD is an inherently rational technique relying on a layer-by-layer (or cluster-by-cluster) assembly of the deposited materials. Similar to the production of layered composite natural or biomimetic materials such as nacre (Finnemore et al., 2012), ALD can be considered as a bio-inspired approach for the fabrication of tailored nanomaterials. ALD proceeds through a sequence of self-terminated gas-solid reactions $\left(\mathrm{R}_{1}\right.$ and $\left.\mathrm{R}_{2}\right)$ that can be expressed as (King et al., 2007):

$$
\begin{aligned}
& \mathrm{R}_{1}:[S]:(O H)_{y}^{*}+x(M L n) \rightarrow[S]:(O H)_{y} M_{x}(L)_{n-y}^{*}+y(H L) \\
& \mathrm{R}_{2}:[S]:(O)_{y} M_{x}(L)_{n-y}^{*}+y H_{2} O \\
& \quad \rightarrow[S]:\left(M_{x} O_{y}\right):(O H)_{y}^{*}+(n-y)(H L)
\end{aligned}
$$

where $S$ represents the surface of the support particle, $y$ is the number of active sites, $x$ is the number of metal-ligand molecules involved in the reaction, $n$ specifies the number of ligands in the metal-ligand $(M, L)$ precursor complex and ${ }^{*}$ indicates the location of the relevant active species in the surface.

Unlike traditional wet-phase or gas-phase deposition (e.g. CVD) schemes, ALD offers digital control of the process since the growth of the materials relies on the number of repeated cycles rather than on the exposure 
tidure okeoncentration of precursors. Moreover, the sub-nm precision (induced by the use of molecular-sized building blocks) enables the exact translation of the material design to an accurately fabricated structure.

\subsection{Particle nanostructuring}

Despite the foundation of ALD as a technique to grow thin, uniform layers of materials (hence its alternative name atomic layer epitaxy), the technique has also been used in the deposition of particle clusters during the initial growth stage (Haukka and Suntola, 1997). This observed deviation from the ideal character of the technique gave rise to an interest in applications that essentially rely on the utilization of a support material of particulate matter for the deposition of an active material. There are several factors affecting growth during the initial stages of ALD. These factors can be divided into three groups as depicted in Fig. 1. We will briefly discuss them with respect to the deposition of a (noble) metal on an oxide-terminated surface:

(1) Looking at the surface properties of the particulate support material, surface-termination-related growth limitations can be the result of the surface density of the reactive adsorption sites (usually in the range of 1-10 OH groups per $\mathrm{nm}^{2}$ for oxide supports (Elam et al., 2007)) and of the preferential interaction of the precursor molecules with certain types of reactive sites. Additionally, surface roughness can also affect the growth (Lu and Stair, 2010).

(2) The binding process of the precursor is also important with a number of key factors such as the steric hindrance of the ligand, poisoning of reactive adsorption sites by contaminants or fragments of the precursor, and the chemisorption kinetics affecting the deposition (Elam et al., 2007; Haukka and Suntola, 1997).

(3) Considering the activation step (usually referring to the second ALD half-cycle, where the activation of the surface via the removal of the remaining ligand and the repopulation of the surface with reactive sites takes place), the interaction of the deposited phase and the support is mainly responsible for a series of events that eventually result in the formation of bigger clusters. Some of the important parameters are the temperature in the deposition chamber, the duration of the dosage times (Feng et al., 2010; Liang et al., 2012), the tendency of metals to minimize their surface energy through the formation of stable metal-metal bonds, and the dewetting of the oxide-metal surface due to the significance of lattice mismatch ( $\mathrm{Lu}$ et al., 2012). Finally, the redistribution of active species during the oxidation-reduction treatment can be considered as an overall affecting condition (Xie et al., 2012).

ALD line-of-sight independency for the precursor delivery enables the deposition in high-aspect-ratio, complex topologies, and high-surface-area substrates. The limiting condition is the presence of a certain surface functionality
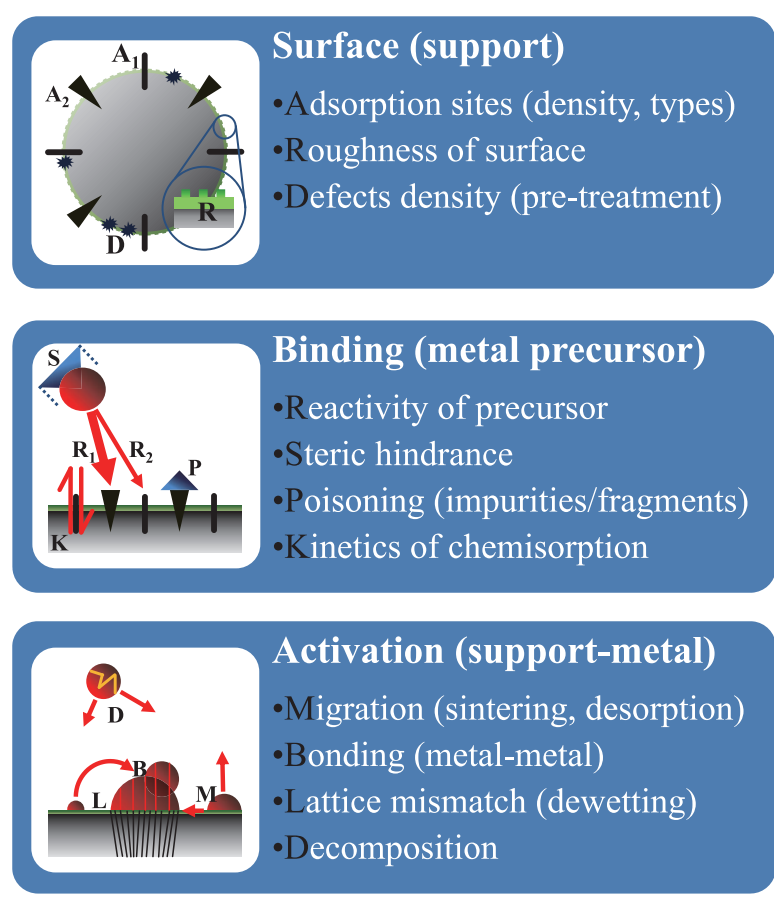

Fig. 1 Island growth dependence on surface-, binding- and activation-related parameters during the ALD of noble metals.

to promote material growth by ALD. Ultrathin seeding layers deposited by ALD (usually $0.2-1.1 \mathrm{~nm}$ thick) can further enhance the growth in support surfaces that show slow/inhibited growth behaviour.

So far, ALD has been used in the modification of oxide supports via the growth of thin layers of oxides, resulting in the fabrication of particulate support materials that can retain some inherited structural properties of the parent material (e.g. external surface area) while modifying others (e.g. acidity, pore size for mesopores, blocking of micropores, surface functionality, etc.). ALD coverageespecially in the initial growth regime - is just a fraction of a true monolayer value. An effort to study the monolayer coverage of various oxides on oxide powders shows that the coverage increases in the order of $\mathrm{SiO}_{2} / \mathrm{TiO}_{2}<\mathrm{TiO}_{2} /$ $\mathrm{SiO}_{2}<\mathrm{Al}_{2} \mathrm{O}_{3} / \mathrm{SiO}_{2}$ or $\mathrm{TiO}_{2}$ (average values of $10 \%, 19 \%$ and $30-57 \%$ as shown in Table 2.

Looking at the different structuring possibilities, ALD can be used for particle nanostructuring, either to induce or inhibit certain composition and structure functionalities. Depending on the growth type of the deposited material, core/shell or core/seed particles (inactive core/active shell or seeds) can be fabricated in an activation scheme. Noble metals (Pt, Pd, Ru, Ir) have been deposited as core/ seed active structures so far, while core/shell particles are usually functionalized with the deposition of transition metal oxide shells (e.g. $\mathrm{TiO}_{2}$ and $\mathrm{ZnO}$ ). ALD has proven its potential to unlock new application areas for core/seed nanoparticles, since it can reach extremely small sizes 
Table 2 Growth per cycle (GPC) of ALD-deposited common oxides $\left(\mathrm{TiO}_{2}, \mathrm{SiO}_{2}, \mathrm{Al}_{2} \mathrm{O}_{3}\right.$ ) on oxide powders (supports)

\begin{tabular}{|c|c|c|c|c|c|}
\hline & & \multicolumn{3}{|c|}{ Support } & \multirow[t]{2}{*}{ References } \\
\hline & & $\mathrm{SiO}_{2}$ & $\mathrm{TiO}_{2}$ & $\mathrm{Al}_{2} \mathrm{O}_{3}$ & \\
\hline \multirow{3}{*}{$\operatorname{GPC}\left(\AA\right.$ cycle $\left.^{-1}\right)$} & $\mathrm{SiO}_{2}$ & - & 0.3 & - & (Kim et al., 2009) \\
\hline & $\mathrm{TiO}_{2}$ & 0.6 & - & - & $\begin{array}{l}\text { (Lei et al., 2012; Mahurin et al., 2006; Sereda et al., 2012; } \\
\text { Williams et al., 2012) }\end{array}$ \\
\hline & $\mathrm{Al}_{2} \mathrm{O}_{3}$ & 1.1 & 2.0 & 1.2 & $\begin{array}{l}\text { (Cronauer et al., 2011; Feng et al., 2010; Feng et al., 2011; } \\
\text { Hakim et al., 2005; Hakim et al., 2006; King et al., 2007; } \\
\text { Lei et al., 2012; Sereda et al., 2012) }\end{array}$ \\
\hline
\end{tabular}

(about $1 \mathrm{~nm}$ ) of deposited particles (clusters) compared to conventional (wet-chemistry-based) techniques. ALD can deposit a variety of different materials (or combinations of them); a comprehensive review of the compounds that can be deposited by ALD was recently presented (Miikkulainen et al., 2013).

In certain applications, it can be desirable to modifyor even fully suppress - the activity of particles; a passivation scheme can yield core/shell particles of a reversed composition (active core/inactive shell). In the case of core/seed particles, this technique was developed as a protection scheme, applicable on the seed-nanoparticles. The most commonly used passivation materials are oxides such as $\mathrm{Al}_{2} \mathrm{O}_{3}$ and $\mathrm{SiO}_{2}$, with the required thickness ranging from values as low as $0.5 \mathrm{~nm}$ up to $50-\mathrm{nm}$ films, depending on the application. Special treatment can tailor the nature of the protective layer to induce a certain accessibility (Canlas et al., 2012; Lu et al., 2012). Moreover, supported active multi-component materials (e.g. multimetallic catalysts) can also be prepared via ALD either in a consecutive deposition scheme (He et al., 2010; He et al., 2012; Molenbroek et al., 1998) or-recently-a mixedmetal ALD process (Christensen et al., 2010; Lei et al., 2012). A schematic depiction of the different possibilities for ALD modifications of different functionalities is shown in Fig. 2.

Thus, ALD offers a 3-stage rational design approach for the synthesis of nanostructured particles. In the first stage, the active phase can be deposited with high precision, either in the form of thin films or nanoparticles. Protection of the active phase can be achieved either by full overcoats (passivation) or partial coverage (preferential growth on the support). Finally, selectivity is induced by manipulating the accessibility of the active phase (in a passive, e.g. thermal treatment, or active, e.g. blocking agent grafting way).

\subsection{Reactor technology}

Materials of a particulate nature often pose challenges during their treatment with ALD due to the high total surface area that needs to be coated and the-often present-requirement of coating high-aspect-ratio structures

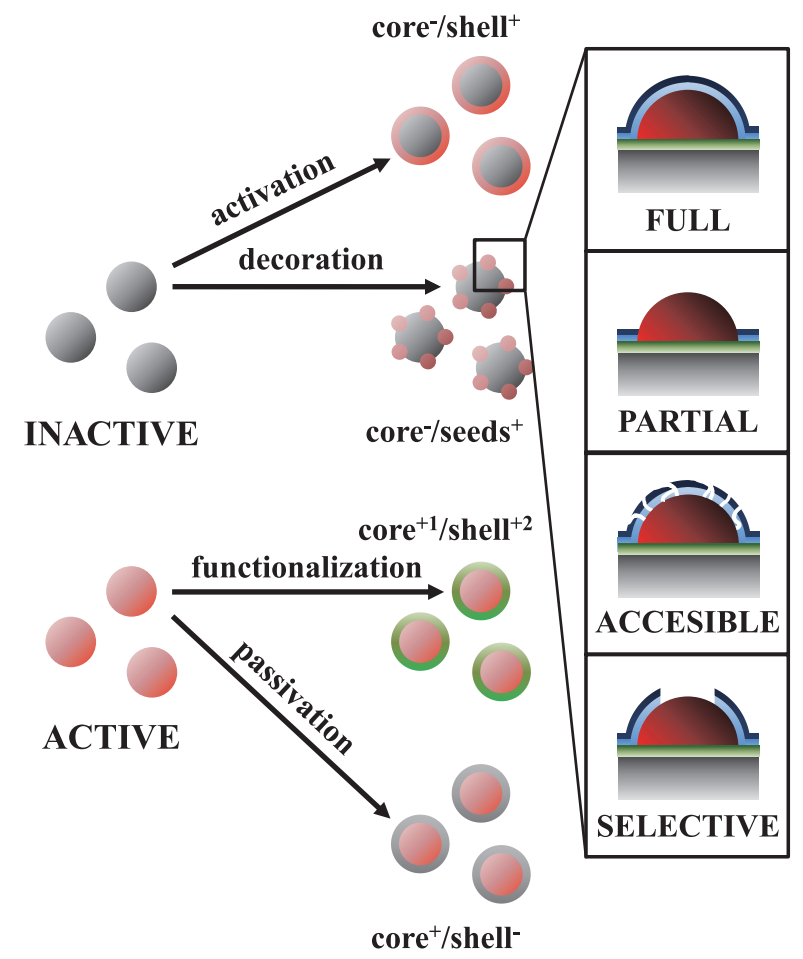

Fig. 2 Functionalization possibilities for active and inactive particles by film or cluster deposition via ALD.

such as micropores. Flow-type reactors for ALD introduced by Microchemistry Ltd. (primarily designed for the treatment of flat substrates) have been also used for the treatment of powders; the MC-120/F-120 being one of the most commonly used reactor type. In the reaction chamber, the reactant, introduced from the top of the fixed powder bed (up to $10 \mathrm{~g}$ ), is allowed to chemisorb and react for a sufficient time to reach saturation (Lakomaa et al., 1992). This reactor configuration yielded consistent saturation coverage $\left( \pm 0.2\right.$ atoms $\left.\mathrm{nm}^{-2}\right)$ but required reasonably high pulsing times (on the hour-scale) due to the relatively high operating pressure of $1-10 \mathrm{kPa}$. Recently, a modification of the reactor cell to a semi-fluidized powder cell was reported for particle ALD (Rauwel et al., 2011).

A viscous-flow ALD reactor (Elam et al., 2002) operating at reduced pressure (120-270 $\mathrm{Pa}$ ) has also been used by researchers in Argonne National Laboratory for ALD 
al $a^{0}$

treatmient of powders. High-surface-area supports (up to $930^{1} \mathrm{~m}^{2} \mathrm{~g}^{-1}$ ) have been effectively coated, at faster saturation exposure times (on the min-scale). Only small batches (up to $1 \mathrm{~g}$ ) of materials have been processed in this viscous-flow reactor type.

Additionally, modifications of conventional ALD reactors aiming at the minimization of gradients (concentration, temperature) during the deposition introduced the use of fluidized bed reactors (Hirva et al., 1994). A fluidized bed ALD reactor operating at low pressure (133-1066 Pa) introduced by Wank et al. (2004) has been extensively used. Large batches of powders (up to $75 \mathrm{~g}$ ) have been effectively coated in this reactor type, successfully proving the scale-up potential. Since many of the powders used as substrates exhibit cohesive behaviour, fluidization assistance methods such as stirring or vibration are typically required. van Ommen et al. (2012) give an overview of the various assistance methods to fluidize nanopowders. Although it may sound counterintuitive, nanopowders can indeed be fluidized. In contrast to particles of say $200 \mu \mathrm{m}$, however, nanoparticles are not fluidized individually but as agglomerates: very dilute structures of around $200 \mu \mathrm{m}$ consisting of $\sim 10^{10}$ primary particles (van Ommen et al., 2012).

Despite the fact that the fluidized bed reactor provided a good scalability potential in terms of the batch handling capabilities, the high total surface area of the powdersand the subsequent need for large amounts of precursor dosing (due to the residence time of the gaseous precursor in the fluidized bed) - called for research focussed on more efficient utilization of the precursor. The use of a rotary reactor operated at very low pressures (less than $133 \mathrm{~Pa}$ ) was suggested (McCormick et al., 2007), in an effort to obtain a static exposure scheme and proper mixing during deposition. In this reactor, fluidization and agitation of the particles is achieved by rotation, and therefore a constant gas flow is not required. However, it was not demonstrated that this reactor was more efficient than a fluidized bed in terms of precursor utilization. Until today, this reactor has been used to coat batches of up to $2 \mathrm{~g}$. A different rotary reactor configuration was recently proposed (Longrie et al., 2012). They operate this reactor at a very low pressure $(<2 \mathrm{~Pa})$. Their system is capable of applying both thermal and plasma-enhanced ALD.

Recently, the atmospheric pressure operation of a fluidized bed ALD reactor was demonstrated for the growth of thin films (Beetstra et al., 2009) and the deposition of highly-dispersed nanoparticles (Goulas and van Ommen, 2013). Although the pulsing times required are longer than the equivalent in low-pressure operation, the process was proven to be efficient in terms of precursor utilization while excluding the need for expensive vacuum equipment. Fluidization at atmospheric pressure is also more attractive from the perspective of the scale-up potential. To our knowledge, the 120 g-batch of $\mathrm{LiMnO}_{4}$ particles

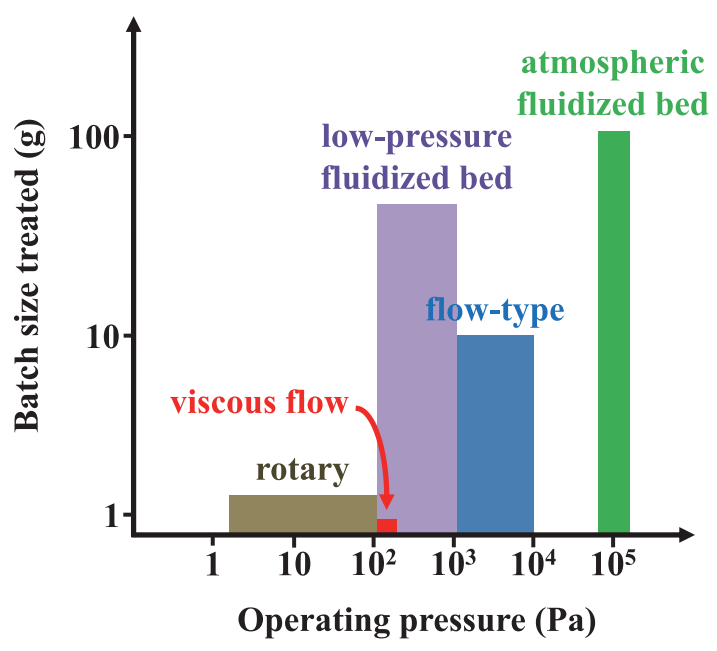

Fig. 3 Categorization of the main research ALD reactors used for particle nanostructuring based on the operating pressure range and maximum batch size reported (logarithmic scales).

coated via ALD in this fluidized batch is the largest amount reported in open literature. The next step is to move from batch to continuous production, e.g. via the pneumatic transport of particles (van Ommen, 2010); research on such reactors is currently being carried out in our group. A summary of the main types of reactors used is given in Fig. 3.

Moreover, certain commercial reactors such as the Beneq P400 (Nevalainen et al., 2012), Ultratech/Cambridge NanoTech Savannah 100 (Sun et al., 2013), Picosun SUNALE R-200B (Williams et al., 2012) and a shower-head reactor from Korean Vacuum Tech. Ltd. (Yoon et al., 2011) have been already used for ALD on particles.

\subsection{Example: deposition of platinum nanoclusters by ALD}

The ability to precisely tailor the structure of particles on a nanoscale gives us a tool to greatly improve metalsupported catalysts, enhancing atom efficiency while minimizing the cost of the expensive and scarce metal of the active phase. Currently, Pt, Ir, Rh are all priced above $\$ 32,000$ per $\mathrm{kg}$. In an effort to establish well-defined structure-reactivity correlations and unravel the role of size in nanocatalysis, materials with well-controlled dimensions in the size of (sub) nanometres have to be delivered. Apart from achieving better material utilization - a high surface-to-volume ratio yields a high amount of active sites per active material mass-different functionalities can also be assessed, due to the changed local reactivity characteristics of nanoparticles (more corners, edges, kinks) compared to their bulkier counterparts. Considering that in the $f c c$ structure of $\mathrm{Pt}$ (atomic diameter of $0.278 \mathrm{~nm}$ ), 12 shell atoms can cover 1 metal atom to form the single full-shell cluster $(n=1)$ (Schmid, 1990), the structure has 


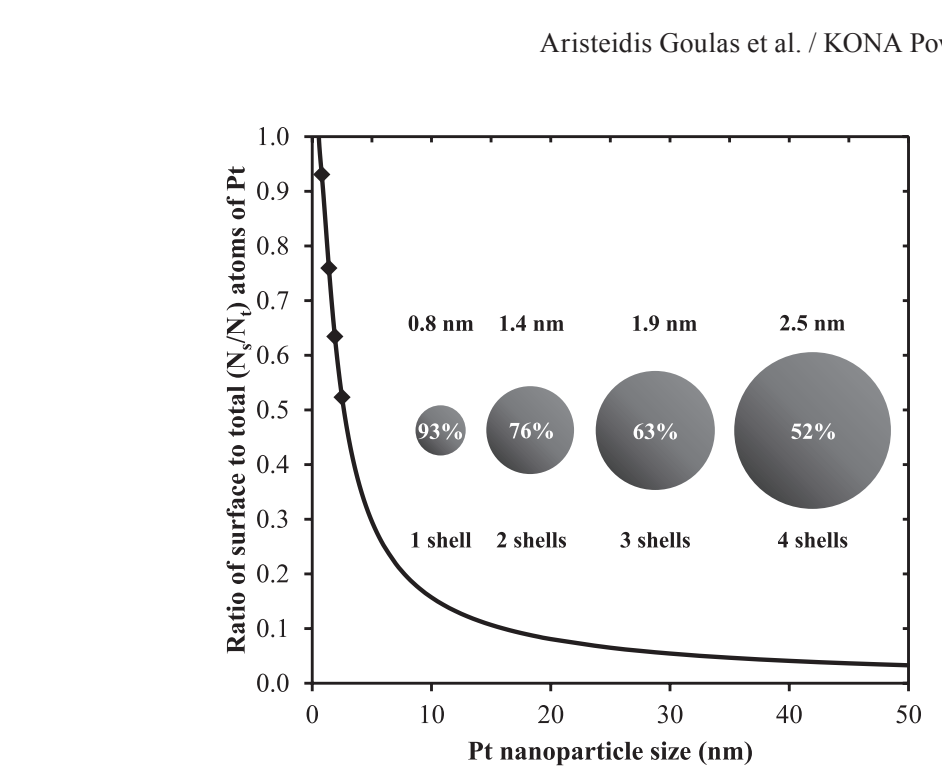

Fig. 4 Ratio of surface to total $\left(N_{\mathrm{s}} / N_{\mathrm{t}}\right)$ atoms as a function of the Pt nanoparticle size (inline graphic indicates the size and percentage of $\mathrm{Pt}$ nanoparticles for 1 to 4 shells in the $f c c$ cluster).

93\% of its atoms on the outer surface (Fig. 4). The $N_{\mathrm{s}} / N_{\mathrm{t}}$ is inversely proportional to the number of shells $\left(n^{-1}\right)$, this decrease can be seen in a $2.5 \mathrm{~nm}$ nanoparticle, where only $52 \%$ of its atoms are directly accessible and thus highlighting the reactivity potential of smaller clusters.

The activity of catalytically promoted reactions is often expressed as the turnover frequency (TOF) which describes the amount of moles converted per mole of the exposed catalyst material. The particle structure (size and shape) can affect the TOF if the reaction is intrinsically dependent on size/shape or is structure-sensitive, while some other reactions are not affected by the size (intrinsically size/shape-independent or structure-insensitive). For structure-sensitive reactions, a positive size effect marks an inversely proportional relationship between particle size and TOF, while a negative size effect shows a proportional interaction (antipathetic particle size-TOF dependence). For structure-insensitive reactions, the main objective during deposition is the maximization of dispersion to achieve optimal use of the catalytic material. Typical Pt-catalysed structure-insensitive reactions are ethylene and cyclohexane hydrogenation, while an example of positively size-dependent reactions are the hydrogenolysis of ethane and the dehydrogenation of cyclohexane (Somorjai and Park, 2008). As seen from Fig. 5, small Pt nanoparticles $(\leq 3 \mathrm{~nm})$ can greatly improve the TOF of structure-sensitive reactions. Additionally, the catalyst selectivity can also be improved by controlling the particle size distribution over a narrow range, as demonstrated for hydrogenation reactions (Somorjai and Park, 2008).

The first report of a supported Pt catalyst fabricated by ALD was the $\mathrm{Pt} / \mathrm{Al}_{2} \mathrm{O}_{3}$ and $\mathrm{Pt} / \mathrm{SiO}_{2}$ hydrogenation catalysts prepared by Lashdaf et al. (2004). The cyclopentadienyl precursor (trimethyl) methylcyclopentadienyl-platinum

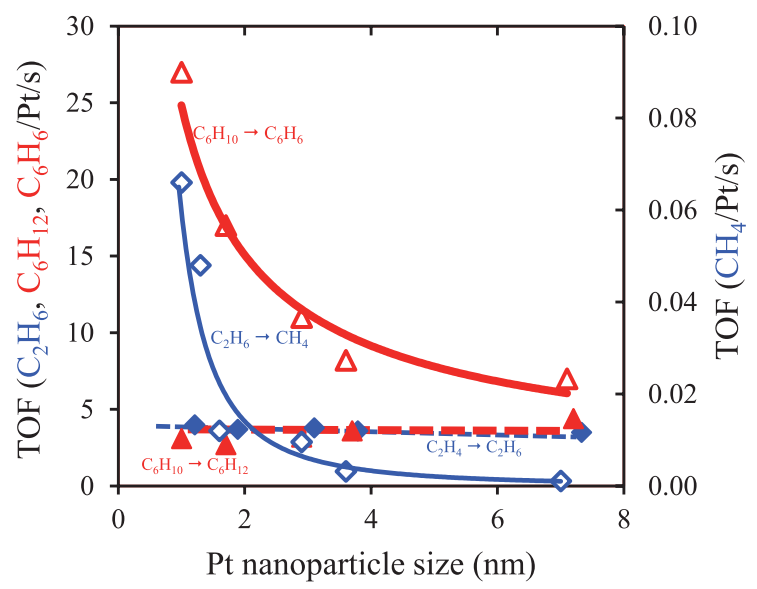

Fig. 5 TOF values for structure-insensitive Pt-catalysed reactions, marks indicate experimentally determined datapoints $\left(\mathrm{C}_{2} \mathrm{H}_{4}\right.$ hydrogenation: blue dotted line and $\bullet$, $\mathrm{C}_{6} \mathrm{H}_{10}$ hydrogenation: red dotted line and $\boldsymbol{\Delta}$ ) and structure-sensitive reactions $\left(\mathrm{C}_{6} \mathrm{H}_{10}\right.$ dehydrogenation: red solid line and $\triangle, \mathrm{C}_{2} \mathrm{H}_{6}$ hydrogenolysis: blue solid line and $\diamond$; plotted on secondary vertical axis) (based on Somorjai and Park (2008)).

(IV) $\left(\mathrm{MeCpPtMe}_{3}\right)$ was used as a source of Pt and air was used for the removal of the organic ligand at $350^{\circ} \mathrm{C}$. For a single exposure of the precursor, larger islands were observed in $\mathrm{SiO}_{2}(3.1 \mathrm{~nm})$ as compared to the $\mathrm{Al}_{2} \mathrm{O}_{3}$ support $(1.2 \mathrm{~nm})$ in consistency with the available number of active $\mathrm{OH}$ groups (proportional to the available surface area and surface density). Additionally, an acetylacetonate Pt precursor ( $\mathrm{Pt}(\mathrm{acac})_{2}$ ) was utilized at lower deposition temperatures of $180-200^{\circ} \mathrm{C}$, which had as a drawback the inclusion of carbon-based impurities of a high concentration ( $\sim 3.5 \mathrm{wt} . \%)$ in the catalyst (Plomp et al., 2008; Vuori et al., 2006).

The importance of $\mathrm{Pt}$ as a catalytic material has driven efforts for deposition on strontium titanate, titania, zirconia and alumina high-surface-area supports in the temperature window of $150-300^{\circ} \mathrm{C}$ (Christensen et al., 2009; Enterkin et al., 2011; Lobo et al., 2012; Setthapun et al., 2010; Xie et al., 2012). Moreover, the technique has also been used for the doping of Co-based Fischer-Tropsch catalysts with small amounts of $\mathrm{Pt}(0.1 \mathrm{wt} . \%)$ that acts as a promoter (Cronauer et al., 2011). Recognizing the technique's potential for creating the high dispersion characteristics necessary in fuel cell applications, ALD has been used for the decoration of relevant carbon-based supports such as carbon aerogel, tungsten-carbide, multi-walled carbon nanotubes, graphene nanosheets and carbon nanotube/graphene oxide hybrid materials (Hsieh et al., 2012; Hsu et al., 2012; Hsueh et al., 2012; King et al., 2008; Sun et al., 2013). Additionally, bimetallic Ru-Pt and Pt-Pd catalysts have also been fabricated (Christensen et al., 2010; Lei et al., 2012). All the aforementioned efforts were carried out in fixed bed reactors that treated small batches of the 
(OAS Topzone). No significant decomposition of ozone was observed during the transportation of the stream to the reactor zone via the reactor distributor. Nitrogen was also used for the intermediate purging pulses that were implemented to evacuate the reactor from the excess of the precursor and the reaction by-products during the ALD half-cycles. During operation, the $\mathrm{TiO}_{2}$ powder was suspended in an $\mathrm{N}_{2}$ flow of $0.20 \mathrm{~L} \mathrm{~min}^{-1}$ (corresponding superficial gas velocity of $4.2 \mathrm{~cm} \mathrm{~s}^{-1}$ ), ensuring that the particles were sufficiently mixed. Fluidization was assisted using a dual vibromotor. The reaction temperature of $250^{\circ} \mathrm{C}$ was maintained by means of an IR-heater with feedback control. A more elaborate description of the set-up is given by Beetstra et al. (2009). The loaded $\mathrm{TiO}_{2}$ nanoparticles were pretreated (heating under inert atmosphere) to ensure a constant initial number of active $\mathrm{OH}$-groups in the surface. The typical pulsing sequence for Pt- $\mathrm{N}_{2}-\mathrm{O}_{3}-\mathrm{N}_{2}$ consisted of exposure times of 3-12 min for $\mathrm{MeCpPtMe}_{3}$, and $10 \mathrm{~min}$ for ozone separated by $\mathrm{N}_{2}$ purging pulses of $10 \mathrm{~min}$.

Optical emission spectrometry (ICP-OES) using a Perkin Elmer Optima 3000 DV spectrometer was used to determine the amount of Pt deposited. The level of carbon impurities in the samples was monitored by IR absorption spectroscopy in a C/S determinator (LECO CS-225). The structure of the deposited islands was determined from TEM images using a FEI Tecnai TF20 microscope equipped with an EDX detector (Oxford Instruments). XRD measurements were carried out with a Bruker D8 Advance diffractometer. The BET surface area of the coated and uncoated samples was determined via $\mathrm{N}_{2}$ adsorption with a Quantachrome Autosorb-6B surface area analyser.

\section{Results and Discussion}

The custom-built fluidized bed ALD reactor consists of a vertical reaction chamber with an inner diameter of $10 \mathrm{~mm}$ that was loaded with $\sim 0.25 \mathrm{~g}$ of nanoparticles, supported on a porous metallic gas distributor. The $\mathrm{TiO}_{2}$ nanoparticles used (Aeroxide P25 from Degussa, $\geq 99.5 \%$ purity) were sieved prior to deposition. Their surface area was $\sim 50 \mathrm{~m}^{2} \mathrm{~g}^{-1}$ and their average primary particle size was $21 \mathrm{~nm}$ with a crystal structure of about $85 \%$ anatase and $15 \%$ rutile. During fluidization, these particles formed agglomerates of around $200 \mu \mathrm{m}$.

The precursor (trimethyl) methylcyclopentadienyl-platinum (IV) (Strem Chemicals, 99\% purity) was utilized as a Pt source. The precursor was transported in the reaction zone by means of a dry nitrogen carrier gas $\left(\mathrm{N}_{2}, 99.999\right.$ vol.\%) that was diverted through the precursor bubbler $\left(50^{\circ} \mathrm{C}\right)$. A dry air stream enriched with ozone (around $1.5 \mathrm{wt} . \%$ ) was used as an oxidizer agent for the removal of the precursor ligands and repopulation of the support surface with active sites. Ozone was obtained by feeding the dry air flow $\left(0.20 \mathrm{~L} \mathrm{~min}^{-1}\right)$ through an ozone generator

Two of the important intrinsic properties of ALD are the self-saturating character of the growth for a single cycle and the linear increase of the amount of material deposited by increasing the amount of cycles. Coating powder batches of increased surface area (up to $14 \mathrm{~m}^{2}$ per sample batch) requires much longer precursor exposure, oxidation and purging times. It has been shown that during the prolonged exposure times, the reactor temperature should be properly controlled to avoid thermal decomposition of the precursor (Liang et al., 2011). When utilizing a lower deposition temperature $\left(250^{\circ} \mathrm{C}\right.$ instead of $\left.320^{\circ} \mathrm{C}\right)$, an indication of the self-saturating ALD characteristic was seen (as shown in Fig. 6) with the Pt loading stabilizing at $\sim 1.6 \mathrm{wt} . \%$ after $12 \mathrm{~min}$ of precursor exposure.

The average Pt particle size from TEM image processing was estimated to be about $1.5 \mathrm{~nm}$ for a Pt pulse of $3 \mathrm{~min}$ and appeared to be stabilized for exposures up to $12 \mathrm{~min}$. Uniform decoration of the support material with Pt nano- 


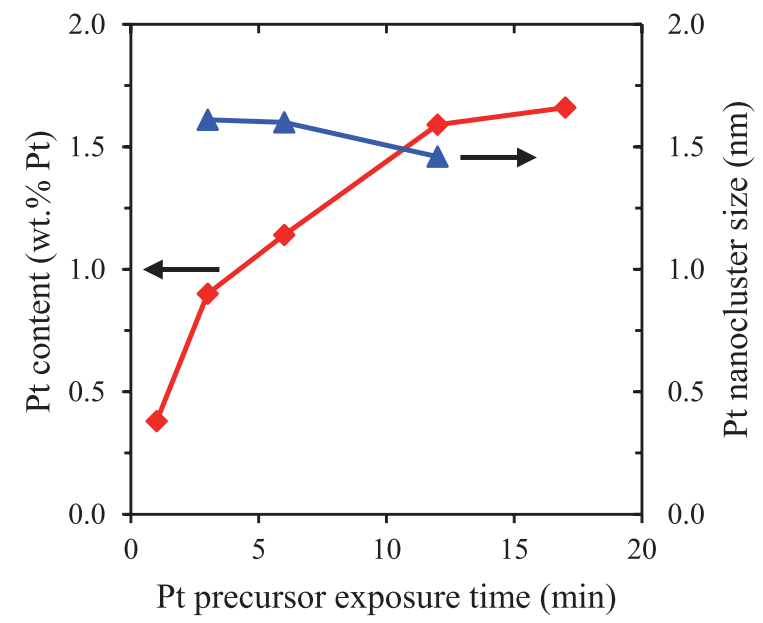

Fig. 6 Estimated Pt content (red line and $\diamond$ ) and nanocluster size (blue line and $\boldsymbol{\Delta}$; on secondary vertical axis) for varied Pt precursor exposure times and 1 ALD cycle.

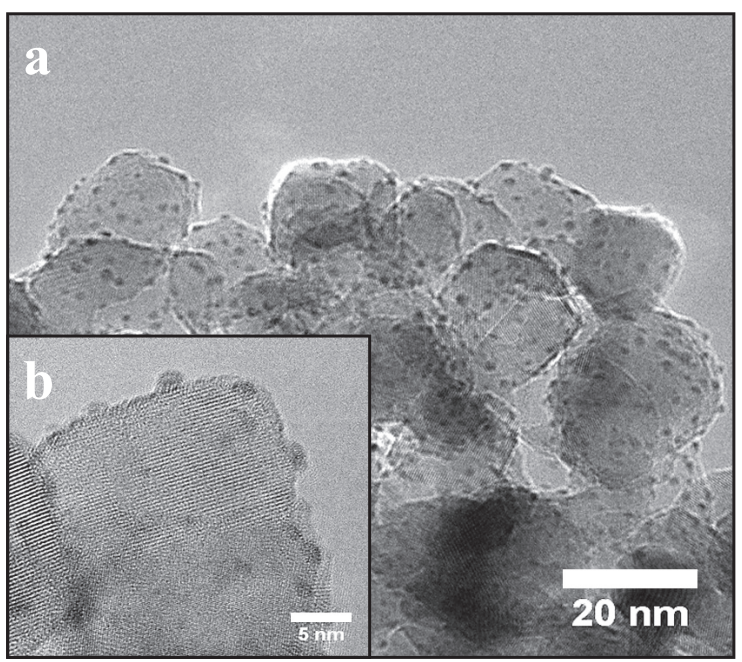

Fig. 7 TEM image of the Pt nanoparticles decorating the surface of the $\mathrm{TiO}_{2}$ support after 1 ALD cycle of 3 min $\mathrm{Pt}$ precursor exposure. The inline image depicts the decoration at the edge of the $\mathrm{TiO}_{2}$ crystal.

clusters was obtained as shown in Fig 7. The particle size distributions presented in Fig. 8 verify that the process was well controlled and resulted in very similar, narrowly distributed particles. Moreover, the TEM pictures indicated that the Pt nanoclusters were nicely distributed over the titania particles. This can be explained by the very open structure of the agglomerates, as well as by their dynamic nature: they constantly break-up and reform into new agglomerates (van Ommen et al., 2012).

Precursor utilization for exposure times in the saturation regime was relatively low: only $\sim 50 \%$ of the Pt precursor provided was eventually loaded in the support. Using ALD for the fabrication of ultra-low loading catalysts, sub-saturated pulses can be implemented to achieve maximum utilization of the precursor. An exposure time of $1 / 4$

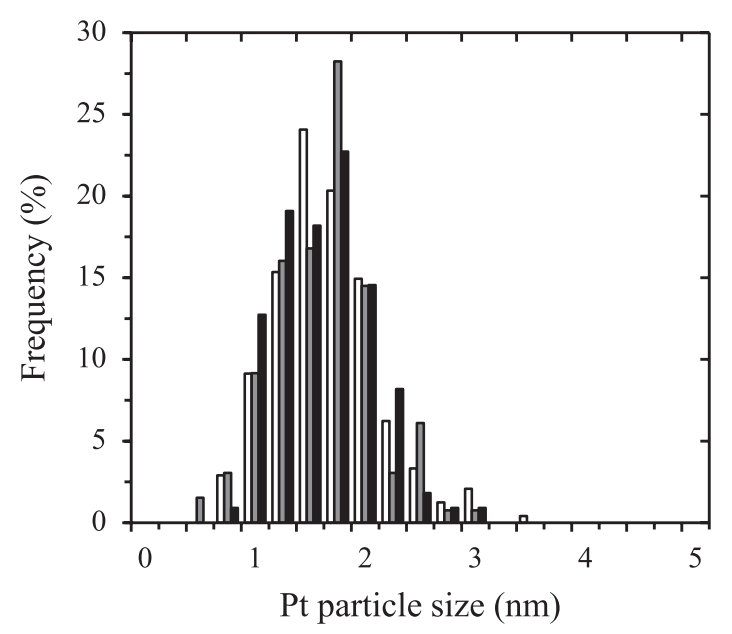

Fig. 8 Pt particle size distributions derived from TEM image processing for samples obtained after $3 \mathrm{~min}$ (white bars), 6 min (grey bars) and 12 min (black bars).

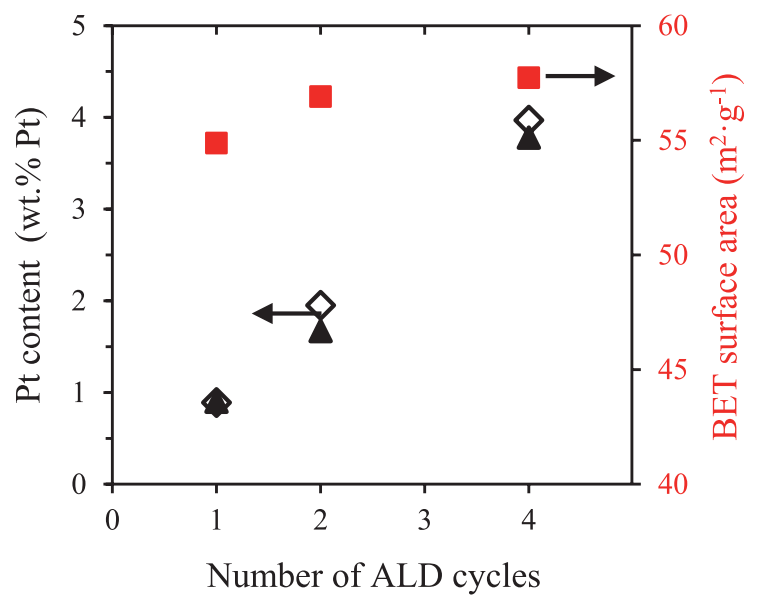

Fig. 9 Pt content measured by ICP ( $\Delta$ ) and predicted loading value for ideal ALD $(\diamond)$ along with specific surface area $(\boldsymbol{\square})$ for 1-4 ALD cycles (Pt content values corrected for changes in surface area after deposition).

the saturation time resulted in a deposition amount of about half of the equivalent amount deposited for operation in the saturation regime. The corresponding precursor utilization was estimated to be $95 \%$ in that case. An estimation of the $E$-factor value was made, considering $\mathrm{Pt}$ / $\mathrm{TiO}_{2}$ as the final product $\left(\sim 10-20 \%\right.$ of the loaded $\mathrm{TiO}_{2}$ is lost as waste during handling). The outlet waste stream contains the gas products of the organic ligand decomposition and the excess amounts of oxidizer gas used $\left(\mathrm{O}_{3} / \mathrm{O}_{2}\right.$, without taking into account $\mathrm{N}_{2}$ ). The equivalent calculated $E$-factor of the deposition process is $\sim 6-7$, fitting in the range of 5-50 that describes processes of the fine chemicals industry (Sheldon, 2007).

Additionally, the loading of the catalyst can be precisely controlled by the number of ALD cycles performed. Fig. 9 

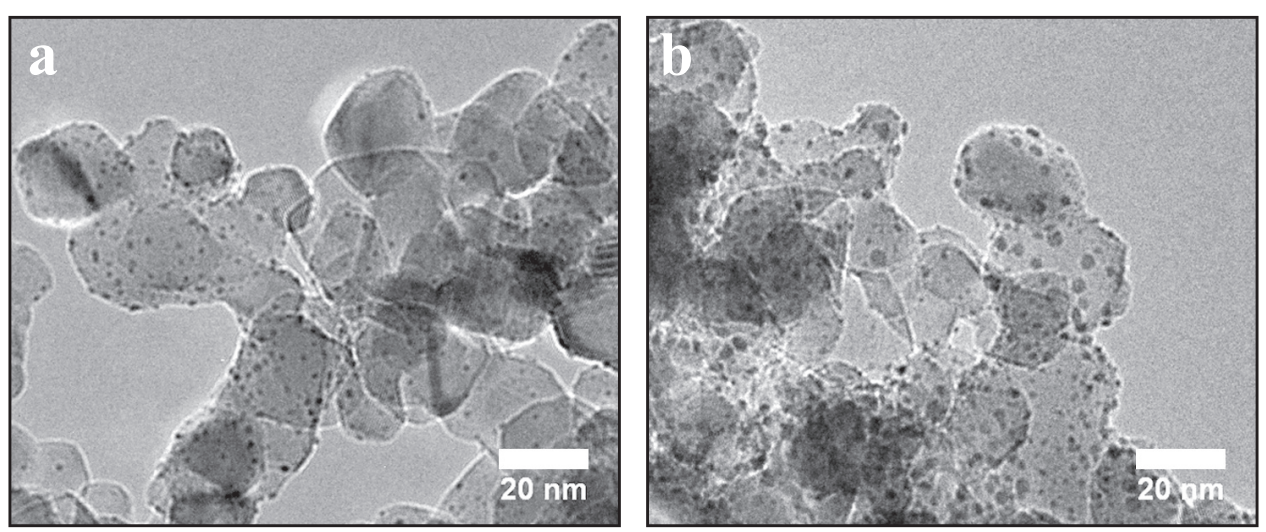

Fig. 10 Overview TEM images of Pt nanoclusters deposited on the $\mathrm{TiO}_{2}$ support for 1 ALD cycle (a) and 5 ALD cycles (b).

presents the measured content of $\mathrm{Pt}(\mathrm{wt} . \%$ of $\mathrm{Pt}$ ) along with the theoretically predicted value for ideal ALD growth, together with the change in value of the specific surface area of the support. Increasing the number of cycles from 1 to 4 shows a monotonic increase of the Pt loading, verifying the proportional relation between the deposited amount and the number of ALD cycles. The surface area showed a small increase of $5 \%$, in agreement with deposition of small Pt nanoclusters on non-porous supports. The loadings of the catalysts obtained here are higher than the ones obtained in a fluidized bed reactor operating at reduced pressures (Zhou et al., 2010). The use of ozone-a more powerful oxidizer-is one possible cause, but the effect of pressure should also be carefully considered in future studies.

The use of ozone allowed the process temperature to be lowered during the oxidizing step. This can have a beneficial effect on the dispersion of the noble metal nanoparticles, as it prevents their sintering to a certain extent. To further probe the dispersion of the Pt nanoclusters, we examined several TEM images, applying image analysis (ImageJ). A sample of 1 ALD cycle deposited for $12 \mathrm{~min}$ exposure time (1.6 wt.\%) and 5 ALD cycles deposited for 5 min exposure time (5.8 wt.\%) are shown in Fig. 10. As the number of cycles increases, the particle nanoclusters increase in size. All the particle size distributions were calculated based on the processing of 100-200 Pt nanoparticles from different images. The presence of Pt (small clusters of darker contrast on the lighter crystalline support material) was further verified by qualitative EDX analysis. As discussed above, the average particle size increased from $1.5 \mathrm{~nm}$ to about $2.3 \mathrm{~nm}$ while the particle size distribution was - for both cases - very narrow (Fig. 11). The possibility of ALD to deposit small nanoparticles, even for high loadings of noble metals, makes it a promising fabrication technique for low-and medium-loading noble metal catalysts.

ALD offers a simple way to control the particle size of

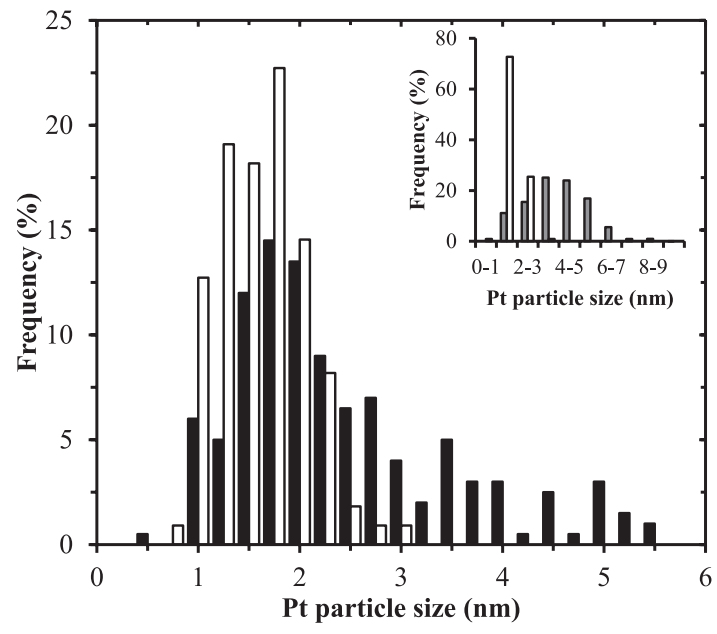

Fig. 11 Particle size distribution derived from TEM image processing for Pt nanoclusters deposited onto the $\mathrm{TiO}_{2}$ support after 1 ALD cycle (white bars) and 5 ALD cycles (black bars). The inline graph shows the particle size distribution of the $1 \mathrm{ALD}$ cycle $\mathrm{Pt} / \mathrm{TiO}_{2}(1.6 \mathrm{wt} . \%$, white bars) and of a $\mathrm{Pt} / \mathrm{TiO}_{2}$ catalyst prepared via photodeposition (1.5 wt.\%, grey bars) (Colón et al., 2010).

$\mathrm{Pt}$, which is illustrated in the inline graph of Fig. 11. The ALD catalyst is compared to a $\mathrm{Pt} / \mathrm{TiO}_{2}$ catalyst of similar loading (1.5 wt.\%) prepared via the photodeposition technique (Colón et al., 2010). The low average particle size obtained by ALD ( $1.5 \mathrm{~nm}$ versus $3.9 \mathrm{~nm}$ ) ensures a higher utilization of the expensive active material. The increase in the noble metal specific surface area $\left(186 \mathrm{~m}^{2} \mathrm{~g}^{-1}\right.$ versus $72 \mathrm{~m}^{2} \mathrm{~g}^{-1}$ ) is expected to contribute positively to the performance of similar catalytic systems. This thus demonstrates that atomic layer deposition using a fluidized bed reactor at atmospheric pressure is an attractive method that combines scalability and high precision for the fabrication of catalysts and other nanostructured materials. 
50. Conclusions and outlook

w

In the past decades, ALD has firmly established its position as a high-precision thin-film manufacturing technique for the microelectronics industry. Realizing the potential of ALD as an integral nanofabrication toolbox for the design, fabrication and modification of advanced materials is opening a new range of possibilities. The application of ALD to particles enables the production of a whole range of novel nanostructured particles for, among others, catalysis, energy conversion and storage, and medical applications.

In this paper, we focused on the fabrication of catalysts by deposition of the active phase (Pt) on a particulate substrate $\left(\mathrm{TiO}_{2} \mathrm{P} 25\right.$ nanoparticles). We demonstrated that ALD is a technique that 1) guarantees efficient use of the precursor; 2) allows precise control of the size and loading; 3) can be used for low and medium loading of catalysts by adjusting the number of repeated cycles; 4) leads to high-quality (low impurities level) end products.

The future demands for the high-volume production of tailored nanostructured materials require innovation in reactor design for ALD processes. Currently, fluidized bed reactors are the first choice for particle ALD, enabling tonne-scale production in the near future. Operating these reactors at low pressures favours the removal of gaseous compounds in the purging steps; however, operation at atmospheric conditions is beneficial for the scale-up potential.

Compared to liquid-based synthesis routes, ALD improves the fabrication compliance with the principles of Green Chemistry: absence of solvents/residues, minimization and easy handling of the reaction by-products (waste) and overall simplification of the production route (all process steps rely on robust gas-solid-based unit operations). The low value of the $E$-factor (comparable to the fine chemicals industry) clearly shows the way to more sustainable production schemes. The high degree of deposition control (size, composition, distribution) highlights the potential for high-end-value products such as noble metal-supported catalysts. Mild temperature and pressure conditions make the technique compatible with temperature-sensitive materials.

As ALD matures further, certain research challenges will have to be overcome: gaps such as the need for research on novel precursors (e.g. for silver and gold) and the requirement of clear understanding of process parameters (effect of pressure, growth mechanisms, and overexposure role on the deviation from ideal behaviour). Many challenging areas related to materials properties and nanostructuring can be addressed in a scalable production scheme offered by ALD. Bringing fundamental science and engineering principles together, ALD is effectively driving surface chemistry at an atomic resolution, while enabling industrial-scale production.

\section{Acknowledgements}

Financial support from the European Research Council (AggloNanoCoat and CONiA projects) is gratefully acknowledged. The authors would like to thank Ms. Andrea Fabre for her careful proofreading of the manuscript.

\section{References}

Beetstra R., Lafont U., Nijenhuis J., Kelder E.M., van Ommen J.R., Atmospheric Pressure Process for Coating Particles Using Atomic Layer Deposition, Chemical Vapor Deposition, 15 (2009) 227-233.

Canlas C.P., Lu J., Ray N.A., Grosso-Giordano N.A., Lee S., Elam J.W., Winans R.E., Van Duyne R.P., Stair P.C., Notestein J.M., Shape-selective sieving layers on an oxide catalyst surface, Nature Chemistry, 4 (2012) 1030-1036.

Christensen S.T., Elam J.W., Rabuffetti F.A., Ma Q., Weigand S.J., Lee B., Seifert S., Stair P.C., Poeppelmeier K.R., Hersam M.C., Bedzyk M.J., Controlled Growth of Platinum Nanoparticles on Strontium Titanate Nanocubes by Atomic Layer Deposition, Small, 5 (2009) 750-757.

Christensen S.T., Feng H., Libera J.L., Guo N., Miller J.T., Stair P.C., Elam, J.W., Supported Ru-Pt Bimetallic Nanoparticle Catalysts Prepared by Atomic Layer Deposition, Nano Letters, 10 (2010) 3047-3051.

Coleman J.N., Liquid Exfoliation of Defect-Free Graphene, Accounts of Chemical Research, 46 (2012) 14-22.

Colón G., Maicu M., Hidalgo M.C., Navío J.A., Kubacka A., Fernández-García M., Gas phase photocatalytic oxidation of toluene using highly active $\mathrm{Pt}$ doped $\mathrm{TiO}_{2}$, Journal of Molecular Catalysis A: Chemical, 320 (2010) 14-18.

Cronauer D.C., Jacobs G., Linganiso L., Kropf A.J., Elam J.W., Christensen S.T., Marshall C.L., Davis B.H., CO Hydrogenation: Exploring Iridium as a Promoter for Supported Cobalt Catalysts by TPR-EXAFS/XANES and Reaction Testing, Catalysis Letters, 141 (2011) 968-976.

Eckelman M.J., Zimmerman J.B., Anastas P.T., Toward Green Nano, Journal of Industrial Ecology, 12 (2008) 316-328.

Elam J.W., Groner M.D., George S.M., Viscous flow reactor with quartz crystal microbalance for thin film growth by atomic layer deposition, Review of Scientific Instruments, 73 (2002) 2981-2987.

Elam J.W., Zinovev A.V., Pellin M.J., Comstock D.J., Hersam M.C., Nucleation and Growth of Noble Metals on Oxide Surfaces Using Atomic Layer Deposition, ECS Transactions, 3 (2007) 271-278.

Ellis N., Yurteri C.U., van Ommen J.R., Development of a continuous nanoparticle coating with electrospraying, in Kim S. D., Kan Y., Lee J. K., Seo Y. C. (Eds.), Fluidization XIIINew paradigm in fluidization engineering, New York: Engineering Conferences International (2010).

Enterkin J.A., Setthapun W., Elam J.W., Christensen S.T., Rabuffetti F.A., Marks L.D., Stair P.C., Poeppelmeier K.R., Marshall C.L., Propane Oxidation over $\mathrm{Pt} / \mathrm{SrTiO}_{3}$ Nanocuboids, ACS Catalysis, 1 (2011) 629-635. 
Felig H. Elam J.W., Libera J.A., Setthapun W., Stair P.C., WPalladium Catalysts Synthesized by Atomic Layer Deposition for Methanol Decomposition, Chemistry of Materials, 22 (2010) 3133-3142.

Feng H., Lu J., Stair P.C., Elam J.W., Alumina over-coating on Pd nanoparticle catalysts by atomic layer deposition: Enhanced stability and reactivity, Catalysis Letters, 141 (2011) 512517.

Ferguson P.P., Todd A.D.W., Dahn J.R., Comparison of mechanically alloyed and sputtered tin-cobalt-carbon as an anode material for lithium-ion batteries, Electrochemistry Communications, 10 (2008) 25-31.

Finnemore A., Cunha P., Shean T., Vignolini S., Guldin S., Oyen M., Steiner U., Biomimetic layer-by-layer assembly of artificial nacre, Nature Communications, 3 (2012) 966:1-6.

Gates B.D., Xu Q., Stewart M., Ryan D., Willson C.G., Whitesides G.M., New Approaches to Nanofabrication: Molding, Printing, and Other Techniques, Chemical Reviews, 105 (2005) 1171-1196.

Goulas A., van Ommen R.J., Atomic layer deposition of platinum clusters on titania nanoparticles at atmospheric pressure, Journal of Materials Chemistry A, 1 (2013) 4647-4650.

Hakim L.F., Blackson J., George S.M., Weimer A.W., Nanocoating Individual Silica Nanoparticles by Atomic Layer Deposition in a Fluidized Bed Reactor, Chemical Vapor Deposition, 11 (2005) 420-425.

Hakim L.F., McCormick J.A., Zhan G.-D., Weimer A.W., Li P., George S.M., Surface Modification of Titania Nanoparticles Using Ultrathin Ceramic Films, Journal of the American Ceramic Society, 89 (2006) 3070-3075.

Haukka S., Suntola T., Advanced Materials Processing by Adsorption Control, Interface Science, 5 (1997) 119-128.

He M., Chernov A.I., Fedotov P.V., Obraztsova E.D., Sainio J., Rikkinen E., Jiang H., Zhu Z., Tian Y., Kauppinen E.I., Niemelä M., Krause A.O.I., Predominant (6,5) Single-Walled Carbon Nanotube Growth on a Copper-Promoted Iron Catalyst, Journal of the American Chemical Society, 132 (2010) 13994-13996.

He M., Liu B., Chernov A.I., Obraztsova E.D., Kauppi I., Jiang H., Anoshkin I., Cavalca F., Hansen T.W., Wagner J.B., Nasibulin A.G., Kauppinen E.I., Linnekoski J., Niemelä M., Lehtonen J., Growth Mechanism of Single-Walled Carbon Nanotubes on Iron-Copper Catalyst and Chirality Studies by Electron Diffraction, Chemistry of Materials, 24 (2012) 1796-1801.

Hirva P., Venäläinen T., Pakkanen T.A., Controlled Deposition from the Gas Phase of Surface Species on Amorphous Supports: Preparation of Ruthenium-Bipyridine Catalysts for 1-Hexene Hydroformylation and Water-Gas Shift Reaction, Journal of Catalysis, 148 (1994) 722-728.

Hsieh C.-T., Liu Y.-Y., Tzou D.-Y., Chen W.-Y., Atomic Layer Deposition of Platinum Nanocatalysts onto Three-Dimensional Carbon Nanotube/Graphene Hybrid, The Journal of Physical Chemistry C, 116 (2012) 26735-26743.

Hsu I.J., Kimmel Y.C., Jiang X., Willis B.G., Chen J.G., Atomic layer deposition synthesis of platinum-tungsten carbide core-shell catalysts for the hydrogen evolution reaction, Chemical Communications, 48 (2012) 1063-1065.
Hsueh Y.-C., Wang C.-C., Kei C.-C., Lin Y.-H., Liu C., Perng T.-P., Fabrication of catalyst by atomic layer deposition for high specific power density proton exchange membrane fuel cells, Journal of Catalysis, 294 (2012) 63-68.

Jancar J., Douglas J.F., Starr F.W., Kumar S.K., Cassagnau P., Lesser A.J., Sternstein S.S., Buehler M.J., Current issues in research on structure-property relationships in polymer nanocomposites, Polymer, 51 (2010) 3321-3343.

Kamat P.V., Quantum Dot Solar Cells. Semiconductor Nanocrystals as Light Harvesters, The Journal of Physical Chemistry C, 112 (2008) 18737-18753.

Kessels W.M.M., Knoops H.C.M., Dielissen S.A.F., Mackus A.J.M., van de Sanden M.C.M., Surface reactions during atomic layer deposition of $\mathrm{Pt}$ derived from gas phase infrared spectroscopy, Applied Physics Letters, 95 (2009) 013114:1-3.

Kim H., Lee H.-B.-R., Maeng W.-J., Applications of atomic layer deposition to nanofabrication and emerging nanodevices, Thin Solid Films, 517 (2009) 2563-2580.

King D.M., Spencer II J.A., Liang X., Hakim L.F., Weimer A.W., Atomic layer deposition on particles using a fluidized bed reactor with in situ mass spectrometry, Surface and Coatings Technology, 201 (2007) 9163-9171.

King J.S., Wittstock A., Biener J., Kucheyev S.O., Wang Y.M., Baumann T.F., Giri S.K., Hamza A.V., Baeumer M., Bent S.F., Ultralow Loading Pt Nanocatalysts Prepared by Atomic Layer Deposition on Carbon Aerogels, Nano Letters, 8 (2008) 2405-2409.

Knijnenburg J.T.N., Hilty F.M., Krumeich F., Zimmermann M.B., Pratsinis S.E., Multimineral nutritional supplements in a nano-CaO matrix, Journal of Materials Research, 28 (2013) 1129-1138.

Lakomaa E.-L., Haukka S., Suntola T., Atomic layer growth of $\mathrm{TiO}_{2}$ on silica, Applied Surface Science, 60-61 (1992) 742-748.

Lashdaf M., Lahtinen J., Lindblad M., Venäläinen T., Krause, A.O.I., Platinum catalysts on alumina and silica prepared by gas- and liquid- phase deposition in cinnamaldehyde hydrogenation, Applied Catalysis A: General, 276 (2004) 129-137.

Laukaitis G., Dudonis J., Milcius D., YSZ thin films deposited by e-beam technique, Thin Solid Films, 515 (2006) 678-682.

Lei Y., Liu B., Lu J., Lobo-Lapidus R.J., Wu T., Feng H., Xia X., Mane A.U., Libera J.A., Greeley J.P., Miller J.T., Elam J.W., Synthesis of Pt-Pd Core-Shell Nanostructures by Atomic Layer Deposition: Application in Propane Oxidative Dehydrogenation to Propylene, Chemistry of Materials, 24 (2012) $3525-3533$.

Li J., Liang X., King D.M., Jiang Y.-B., Weimer A.W., Highly dispersed Pt nanoparticle catalyst prepared by atomic layer deposition, Applied Catalysis B: Environmental, 97 (2010) $220-226$

Li Y., Somorjai G.A., Nanoscale Advances in Catalysis and Energy Applications, Nano Letters, 10 (2010) 2289-2295.

Liang X., Zhou Y., Li J., Weimer A., Reaction mechanism studies for platinum nanoparticle growth by atomic layer deposition, Journal of Nanoparticle Research, 13 (2011) 3781-3788.

Liang X., Lyon L., Jiang Y.-B., Weimer A., Scalable synthesis of palladium nanoparticle catalysts by atomic layer deposition, 

Stach E.A., Mane A., Lei Y., Elam J., Miller J.T., Understanding the Chemistry of $\mathrm{H}_{2}$ Production for 1-Propanol Reforming: Pathway and Support Modification Effects, ACS Catalysis, 2 (2012) 2316-2326.

Longrie D., Deduytsche D., Haemers J., Driesen K., Detavernier C., A rotary reactor for thermal and plasma-enhanced atomic layer deposition on powders and small objects, Surface and Coatings Technology 213 (2012) 183-191.

Lu J., Stair P.C., Low-Temperature ABC-Type Atomic Layer Deposition: Synthesis of Highly Uniform Ultrafine Supported Metal Nanoparticles, Angewandte Chemie International Edition, 49 (2010) 2547-2551.

Lu J., Fu B., Kung M.C., Xiao G., Elam J.W., Kung H.H., Stair P.C., Coking- and Sintering-Resistant Palladium Catalysts Achieved Through Atomic Layer Deposition, Science, 335 (2012) 1205-1208.

Mahurin S., Bao L., Yan W., Liang C., Dai S., Atomic layer deposition of $\mathrm{TiO}_{2}$ on mesoporous silica, Journal of NonCrystalline Solids, 352 (2006) 3280-3284.

McCormick J.A., Cloutier B.L., Weimer A.W., George S.M., Rotary reactor for atomic layer deposition on large quantities of nanoparticles, Journal of Vacuum Science \& Technology A: Vacuum, Surfaces, and Films, 25 (2007) 67-74.

Miikkulainen V., Leskelä M., Ritala M., Puurunen R.L., Crystallinity of inorganic films grown by atomic layer deposition: Overview and general trends, Journal of Applied Physics, 113 (2013) 021301:1-101.

Minnermann M., Grossmann H.K., Pokhrel S., Thiel K., Hagelin-Weaver H., Bäumer M., Mädler L., Double flame spray pyrolysis as a novel technique to synthesize aluminasupported cobalt fischer-tropsch catalysts, Catalysis Today, 214 (2013) 90-99.

Molenbroek A.M., Haukka S., Clausen B.S., Alloying in Cu/Pd Nanoparticle Catalysts, The Journal of Physical Chemistry B, 102 (1998) 10680-10689.

Nevalainen K., Isomäki N., Honkanen M., Suihkonen R., McNally T., Harkin-Jones E., Syrjälä S., Vuorinen J., Järvelä P., Melt-compounded nanocomposites of titanium dioxide atomic-layer-deposition-coated polyamide and polystyrene powders, Polymers for Advanced Technologies, 23 (2012) 357-366.

Plomp A.J., Vuori H., Krause A.O.I., de Jong K.P., Bitter J.H., Particle size effects for carbon nanofiber supported platinum and ruthenium catalysts for the selective hydrogenation of cinnamaldehyde, Applied Catalysis A: General, 351 (2008) 9-15.

Rauwel E., Galeckas A., Rauwel P., Nilsen O., Walmsley J., Rytter E., Fjellvaåg H., ALD Applied to Conformal Coating of Nanoporous $\gamma$-Alumina: Spinel Formation and Luminescence Induced by Europium Doping, ECS Transactions, 41 (2011) 123-130.

Schmid G., Clusters and colloids: bridges between molecular and condensed material, Endeavour, 14 (1990) 172-178.

Sereda G., Marshall C., Libera J.A., Dreessen J., Grady A., Turner M., Effect of Atomic Layer Deposition Support Thickness on Structural Properties and Oxidative Dehydro-

genation of Propane on Alumina- and Titania-Supported Vanadia, Catalysis Letters, 142 (2012) 399-407.

Setthapun W., Williams W.D., Kim S.M., Feng H., Elam J.W., Rabuffetti F.A., Poeppelmeier K.R., Stair P.C., Stach E.A., Ribeiro F.H., Miller J.T., Marshall C.L., Genesis and Evolution of Surface Species during Pt Atomic Layer Deposition on Oxide Supports Characterized by in Situ XAFS Analysis and Water-Gas Shift Reaction, The Journal of Physical Chemistry C, 114 (2010) 9758-9771.

Sheldon R.A., Organic synthesis. Past, present and future, Chemistry and Industry (London), 23 (1992) 903-906.

Sheldon R.A., The E Factor: fifteen years on, Green Chemistry, 9 (2007) 1273-1283.

Somorjai G.A., Park J.Y., Colloid Science of Metal Nanoparticle Catalysts in 2D and 3D Structures. Challenges of Nucleation, Growth, Composition, Particle Shape, Size Control and Their Influence on Activity and Selectivity, Topics in Catalysis, 49 (2008) 126-135.

Stepuk A., Krämer K.W., Stark W.J., Flame synthesis of complex fluoride-based nanoparticles as upconversion phosphors, KONA Powder and Particle Journal, 30 (2012) 267-275.

Sun S., Zhang G., Gauquelin N., Chen N., Zhou J., Yang S., Chen W., Meng X., Geng D., Banis M.N., Li R., Ye S., Knights S., Botton G.A., Sham T.-K., Sun X., Single-atom Catalysis Using Pt/Graphene Achieved through Atomic Layer Deposition, Scientific Reports, 3 (2013) 1775:1-9.

van Ommen J.R., (2010): WO Patent Application, 2010/100235 A1.

van Ommen J.R., Valverde J., Pfeffer R., Fluidization of nanopowders: a review, Journal of Nanoparticle Research, 14 (2012) 1-29.

Vuori H., Lindblad M., Outi A., Krause I., Preparation of noble metal catalysts by atomic layer deposition: FTIR studies, in Gaigneuax E.M., Devillers M., De Vos D.E., Hermans S., Jacobs P.A., Ruiz P., (Eds.), Studies in Surface Science and Catalysis, Louvain-la-Neuve: Elsevier, 2006.

Wank J.R., George S.M., Weimer A.W., Coating Fine Nickel Particles with $\mathrm{Al}_{2} \mathrm{O}_{3}$ Utilizing an Atomic Layer Deposition-Fluidized Bed Reactor (ALD-FBR), Journal of the American Ceramic Society, 87 (2004) 762-765.

Wegener S.L., Marks T.J., Stair P.C., Design Strategies for the Molecular Level Synthesis of Supported Catalysts, Accounts of Chemical Research, 45 (2011) 206-214.

Williams P.A., Ireland C.P., King P.J., Chater P.A., Boldrin P., Palgrave R.G., Claridge J.B., Darwent J.R., Chalker P.R., Rosseinsky M.J., Atomic layer deposition of anatase $\mathrm{TiO}_{2}$ coating on silica particles: growth, characterization and evaluation as photocatalysts for methyl orange degradation and hydrogen production, Journal of Materials Chemistry, 22 (2012) 20203-20209.

Xie H., Lu J., Shekhar M., Elam J.W., Delgass W.N., Ribeiro F.H., Weitz E., Poeppelmeier K.R., Synthesis of NaStabilized Nonporous t- $\mathrm{ZrO}_{2}$ Supports and $\mathrm{Pt} / \mathrm{t}-\mathrm{ZrO}_{2}$ Catalysts and Application to Water-Gas-Shift Reaction, ACS Catalysis, 3 (2012) 61-73.

Yoon J.-H., Jung S.-C., Kim J.-S., Photocatalytic effects for the $\mathrm{TiO}_{2}$-coated phosphor materials, Materials Chemistry and Physics, 125 (2011) 342-346. 
Yorterike.U., Hartman R.P.A., Marijnissen J.C.M., Producing WPharmaceutical particles via Electrospraying with an emphasis on nano and nano structured particles-A review, KONA Powder and Particle Journal, 28 (2010) 91-115.
Zhou Y., King D.M., Liang X., Li J., Weimer A.W., Optimal preparation of $\mathrm{Pt} / \mathrm{TiO}_{2}$ photocatalysts using atomic layer deposition, Applied Catalysis B: Environmental, 101 (2010) 54-60.

\section{Author's short biography}
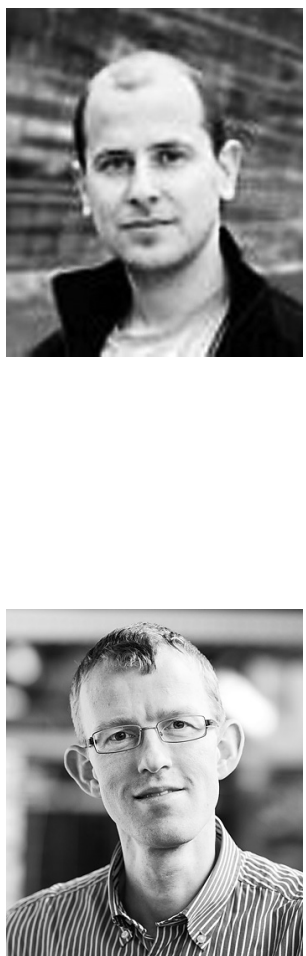

\section{Aristeidis Goulas}

Aristeidis Goulas received his Dipl. Eng. in chemical engineering from Aristotle University of Thessaloniki in 2008 and his MSc degree in sustainable energy technology from Delft University of Technology in 2011. He then joined the Product and Process Engineering group (Delft University of Technology) as a researcher. His work focuses on gas-phase nanostructuring techniques for the fabrication of novel nanostructured materials.

\section{J. Ruud van Ommen}

J. Ruud van Ommen received his MSc degree in chemical engineering in 1997, followed by a Ph.D. in 2001, both from Delft University of Technology (the Netherlands). He has been a faculty member at Delft since, with stints at Chalmers University of Technology (Sweden, 2004/2005) and the University of Colorado Boulder (USA, 2009). In 2011, he received an ERC starting grant to investigate the interplay between the agglomeration and coating of nanoparticles in the gas phase. Currently, he is an associate professor at Delft University, leading a research team with the focus on scalable processes to make nanostructured materials. 